Article

\title{
Common Fixed Point and Endpoint Theorems for a Countable Family of Multi-Valued Mappings
}

\author{
Hüseyin Işık ${ }^{1}\left(\mathbb{D}\right.$, Babak Mohammadi ${ }^{2, *}$ (D) Choonkil Park ${ }^{3, *(1)}$ and Vahid Parvaneh ${ }^{4}$ (1) \\ 1 Department of Mathematics, Faculty of Science and Arts, Muş Alparslan University, 49250 Muş, Turkey; \\ isikhuseyin76@gmail.com \\ 2 Department of Mathematics, Marand Branch, Islamic Azad University, Marand, Iran \\ 3 Research Institute for Natural Sciences, Hanyang University, Seoul 04763, Korea \\ 4 Department of Mathematics, Gilan-E-Gharb Branch, Islamic Azad University, Gilan-E-Gharb, Iran; \\ zam.dalahoo@gmail.com \\ * Correspondence: bmohammadi@marandiau.ac.ir (B.M.); baak@hanyang.ac.kr (C.P.)
}

Received: 4 December 2019; Accepted: 24 December 2019; Published: 21 February 2020

Abstract: We prove some common fixed point and endpoint theorems for a countable infinite family of multi-valued mappings, as well as Allahyari et al. (2015) did for self-mappings. An example and an application to a system of integral equations are given to show the usability of the results.

Keywords: common fixed point; endpoint; infinite family; multi-valued mapping; (HS) property

\section{Introduction}

The study of common fixed point for a family of contraction mappings was initiated by Ćirić in [1]. Recently, in 2015, Allahyari et al. [2] introduced some new type of contractions for a countable family of contraction self-mappings and studied common fixed point for them.

On the other hand, existence of a fixed point for multi-valued mappings has been important for many mathematicians. In 1969, Nadler [3] extended the Banach contraction principle to multi-valued mappings. After that, many authors generalized Nadler's result in different ways (see, for instance [4-8]).

In 2012, Samet et al. [9] introduced the notion of $\alpha$-admisssible mappings and a new type of contraction to a mapping $T: X \rightarrow X$ called $\alpha$ - $\psi$-contractive mapping, that is, $\alpha(x, y) d(T x, T y) \leqslant \psi(d(x, y))$ for all $x, y \in X$. This result generalized and improved many existing fixed point results. In the last few years, some authors have extended the notion of $\alpha$-admisssibility and $\alpha-\psi$-contraction to multi-valued mappings (see, $[10,11]$ ). In addition, common fixed point for a finite family or countable family of multi-valued mappings has been studied by some researchers (see, for example [12-16]).

The aim of this paper is to extend the new type of common contractivity for a family of mappings, introduced by Allahyari et al. (2015), to $\alpha$-admisssible multi-valued mappings.

Let $(X, d)$ be a metric space, $2^{X}$ the set of all nonempty subsets of $X$, and $\mathcal{C} \mathcal{L}(X)$ the set of all nonempty closed subsets of $X$. Assume that $\mathcal{H}$ is the generalized Hausdorff metric on $\mathcal{C} \mathcal{L}(X)$ defined by

$$
\mathcal{H}(A, B)= \begin{cases}\max \left\{\sup _{x \in A} D(x, B), \sup _{y \in B} D(y, A)\right\}, & \text { if it exists, } \\ \infty, & \text { otherwise, }\end{cases}
$$

for all $A, B \in \mathcal{C} \mathcal{L}(X)$, where $D(x, B)=\inf _{y \in B} d(x, y)$. Let $T: X \rightarrow 2^{X}$ is a multi-valued mapping. An element $x \in X$ is said to be a fixed point of $T$ if $x \in T x$, and $x$ is called an endpoint of $T$ whenever $T x=\{x\}$. 


\section{Main Results}

Now, we are ready to state and prove the main results of this study.

Definition 1. Let $X$ be an arbitrary space and $\alpha: X \times X \rightarrow[0, \infty)$ be a function. Assume that $T_{n}: X \rightarrow 2^{X}(n=$ $1,2, \ldots)$ is a family of multi-valued mappings. We say that $\left\{T_{n}\right\}$ is $\alpha$-admissible whenever for each $x \in X$ and $y \in T_{n} x$ with $\alpha(x, y) \geqslant 1$, we have $\alpha(y, z) \geqslant 1$ for all $z \in T_{n+1} y$.

Theorem 1. Let $(X, d)$ be a complete metric space and $0<a_{i, j}(i, j=1,2, \ldots)$ with $a_{i, i+1} \neq 1$ for all $i=1,2, \ldots$ satisfy:

(i) for each $j, \overline{\lim }_{i \rightarrow \infty} a_{i, j}<1$;

(ii) $\sum_{n=1}^{\infty} A_{n}<\infty$, where $A_{n}=\prod_{i=1}^{n} \frac{a_{i, i+1}}{1-a_{i, i+1}}$.

Let $\alpha: X \times X \rightarrow[0, \infty)$ be a given function and $\left\{T_{n}\right\}$ be a sequence of multi-valued operators $T_{n}: X \rightarrow \mathcal{C} \mathcal{L}(X)(n=$ $1,2, \ldots)$ such that

$$
\alpha(x, y) \mathcal{H}\left(T_{i} x, T_{j} y\right) \leqslant a_{i, j}\left[D\left(x, T_{j} y\right)+D\left(y, T_{i} x\right)\right]
$$

for all $x, y \in X ; i, j=1,2, \ldots$ with $x \neq y$ and $i \neq j$. Moreover, assume that the following assertions hold:

(iii) there exist $x_{0} \in X$ and $x_{1} \in T_{1} x_{0}$ with $x_{0} \neq x_{1}$ and $\alpha\left(x_{0}, x_{1}\right) \geqslant 1$;

(iv) $\left\{T_{n}\right\}$ is $\alpha$-admissible;

(v) for each sequence $\left\{x_{n}\right\}$ in $X$ with $\alpha\left(x_{n}, x_{n+1}\right) \geqslant 1$ for all $n$ and $x_{n} \rightarrow x$, we have $\alpha\left(x_{n}, x\right) \geqslant 1$ for all $n$.

Then each $T_{n}$ have a common fixed point in $X$.

Proof. Using (iii) and (2), we have

$$
\begin{aligned}
D\left(x_{1}, T_{2} x_{1}\right) & \leqslant \alpha\left(x_{0}, x_{1}\right) \mathcal{H}\left(T_{1} x_{0}, T_{2} x_{1}\right) \\
& \leqslant a_{1,2}\left[D\left(x_{0}, T_{2} x_{1}\right)+D\left(x_{1}, T_{1} x_{0}\right)\right] \\
& =a_{1,2} D\left(x_{0}, T_{2} x_{1}\right) \\
& \leqslant a_{1,2}\left[d\left(x_{0}, x_{1}\right)+D\left(x_{1}, T_{2} x_{1}\right)\right]
\end{aligned}
$$

which implies

$$
D\left(x_{1}, T_{2} x_{1}\right) \leqslant \frac{a_{1,2}}{1-a_{1,2}} d\left(x_{0}, x_{1}\right)<\frac{a_{1,2}}{1-a_{1,2}} p d\left(x_{0}, x_{1}\right),
$$

where $p>1$ is a fixed number. From the above inequality, there exists $x_{2} \in T_{2} x_{1}$ such that $d\left(x_{1}, x_{2}\right)<$ $\frac{a_{1,2}}{1-a_{1,2}} p d\left(x_{0}, x_{1}\right)$. Since $\left\{T_{n}\right\}$ is $\alpha$-admissible, we have $\alpha\left(x_{1}, x_{2}\right) \geqslant 1$. Similarly,

$$
D\left(x_{2}, T_{3} x_{2}\right) \leqslant \frac{a_{2,3}}{1-a_{2,3}} d\left(x_{1}, x_{2}\right)<\frac{a_{2,3}}{1-a_{2,3}} \frac{a_{1,2}}{1-a_{1,2}} p d\left(x_{0}, x_{1}\right),
$$

and so there exists $x_{3} \in T_{3} x_{2}$ such that $d\left(x_{2}, x_{3}\right)<\frac{a_{2,3}}{1-a_{2,3}} \frac{a_{1,2}}{1-a_{1,2}} p d\left(x_{0}, x_{1}\right)$. Continuing this process, we obtain a sequence $\left\{x_{n}\right\}$ in $X$ such that $x_{n+1} \in T_{n+1} x_{n}, \alpha\left(x_{n}, x_{n+1}\right) \geqslant 1$, and

$$
d\left(x_{n}, x_{n+1}\right)<A_{n} p d\left(x_{0}, x_{1}\right), \quad \text { for all } n=1,2, \ldots
$$

For any $n, m \in \mathbb{N}$ with $n<m$, from triangle inequality, we get

$$
d\left(x_{n}, x_{m}\right) \leqslant \sum_{k=n}^{m-1} d\left(x_{k}, x_{k+1}\right) \leqslant \sum_{k=n}^{m-1} A_{k} p d\left(x_{0}, x_{1}\right) \rightarrow 0
$$


as $n, m \rightarrow \infty$. Therefore, we have shown that $\left\{x_{n}\right\}$ is a Cauchy sequence. Since $(X, d)$ is complete, there exists $x \in X$ such that $x_{n} \rightarrow x$. From $(v)$, we get $\alpha\left(x_{n}, x\right) \geqslant 1$ for all $n$. Now, we shall show that $x$ is a common fixed point of $T_{n}$. Let $m$ be an arbitrary positive integer. Then, for any $n \in \mathbb{N}$, we have

$$
\begin{aligned}
D\left(x, T_{m} x\right) & \leqslant d\left(x, x_{n}\right)+D\left(x_{n}, T_{m} x\right) \\
& \leqslant d\left(x, x_{n}\right)+\alpha\left(x_{n-1} x\right) \mathcal{H}\left(T_{n} x_{n-1}, T_{m} x\right) \\
& \leqslant d\left(x, x_{n}\right)+a_{n, m}\left[D\left(x_{n-1}, T_{m} x\right)+D\left(x, T_{n} x_{n-1}\right)\right] \\
& \leqslant d\left(x, x_{n}\right)+a_{n, m}\left[D\left(x_{n-1}, T_{m} x\right)+d\left(x, x_{n}\right)\right] .
\end{aligned}
$$

Taking $\overline{\lim }$ in both sides of the above inequality, as $n \rightarrow \infty$, we get

$$
D\left(x, T_{m} x\right) \leqslant\left(\overline{\lim }_{n \rightarrow \infty} a_{n, m}\right) D\left(x, T_{m} x\right),
$$

which implies $D\left(x, T_{m} x\right)=0$ and so $x \in T_{m} x$.

Theorem 2. Let $(X, d)$ be a complete metric space and $0<a_{i, j}(i, j=1,2, \ldots)$ with $a_{i, i+1} \neq 1$ for all $i=1,2, \ldots$ satisfy:

(i) for each (j), $\overline{\lim }_{i \rightarrow \infty} a_{i, j}<1$;

(ii) $\sum_{n=1}^{\infty} A_{n}<\infty$ where $A_{n}=\prod_{i=1}^{n} \frac{a_{i, i+1}}{1-a_{i, i+1}}$.

Let $\alpha: X \times X \rightarrow[0, \infty)$ be a given function and $\left\{T_{n}\right\}$ be a sequence of multi-valued operators $T_{n}: X \rightarrow \mathcal{C L}(X)(n=$ $1,2, \ldots)$ such that

$$
\alpha(x, y) \mathcal{H}\left(T_{i} x, T_{j} y\right) \leqslant a_{i, j} \max \left\{d(x, y), D\left(x, T_{i} x\right), D\left(y, T_{j} y\right), D\left(x, T_{j} y\right), D\left(y, T_{i} x\right)\right\},
$$

for all $x, y \in X ; i, j=1,2, \ldots$ with $x \neq y$ and $i \neq j$. Moreover, assume that the following assertions hold:

(iii) there exist $x_{0} \in X$ and $x_{1} \in T_{1} x_{0}$ with $x_{0} \neq x_{1}$ and $\alpha\left(x_{0}, x_{1}\right) \geqslant 1$;

(iv) $\left\{T_{n}\right\}$ is $\alpha$-admissible;

(v) for each sequence $\left\{x_{n}\right\}$ in $X$ with $\alpha\left(x_{n}, x_{n+1}\right) \geqslant 1$ for all $n$ and $x_{n} \rightarrow x$, we have $\alpha\left(x_{n}, x\right) \geqslant 1$ for all $n$.

Then each $T_{n}$ have a common fixed point in $X$.

Proof. By (iii) and (4), we have

$$
\begin{aligned}
D\left(x_{1}, T_{2} x_{1}\right) & \leqslant \alpha\left(x_{0}, x_{1}\right) \mathcal{H}\left(T_{1} x_{0}, T_{2} x_{1}\right) \\
& \leqslant a_{1,2} \max \left\{d\left(x_{0}, x_{1}\right), D\left(x_{0}, T_{1} x_{0}\right), D\left(x_{1}, T_{2} x_{1}\right), D\left(x_{0}, T_{2} x_{1}\right), D\left(x_{1}, T_{1} x_{0}\right)\right\} \\
& \leqslant a_{1,2}\left[d\left(x_{0}, x_{1}\right)+D\left(x_{1}, T_{2} x_{1}\right)\right],
\end{aligned}
$$

which implies

$$
D\left(x_{1}, T_{2} x_{1}\right) \leqslant \frac{a_{1,2}}{1-a_{1,2}} d\left(x_{0}, x_{1}\right)<\frac{a_{1,2}}{1-a_{1,2}} p d\left(x_{0}, x_{1}\right),
$$

which $p>1$ is a fixed number. From the above inequality, there exists $x_{2} \in T_{2} x_{1}$ such that $d\left(x_{1}, x_{2}\right)<$ $\frac{a_{1,2}}{1-a_{1,2}} p d\left(x_{0}, x_{1}\right)$. Continuing in this manner and as in proof of Theorem 1 , we obtain a sequence $\left\{x_{n}\right\}$ with 
$\alpha\left(x_{n}, x_{n+1}\right) \geqslant 1$ and $x \in X$ such that $x_{n} \rightarrow x$. Using $(v)$, we get $\alpha\left(x_{n}, x\right) \geqslant 1$ for all $n$. Next, we show that $x$ is a common fixed point of $T_{n}$. Let $m$ be an arbitrary positive integer. Then, for any $n \in \mathbb{N}$, we have

$$
\begin{aligned}
D\left(x, T_{m} x\right) \leqslant & d\left(x, x_{n}\right)+D\left(x_{n}, T_{m} x\right) \\
\leqslant & d\left(x, x_{n}\right)+\alpha\left(x_{n-1}, x\right) \mathcal{H}\left(T_{n} x_{n-1}, T_{m} x\right) \\
\leqslant & d\left(x, x_{n}\right)+a_{n, m} \max \left\{d\left(x_{n-1}, x\right), D\left(x_{n-1}, T_{n} x_{n-1}\right), D\left(x, T_{m} x\right),\right. \\
& \left.D\left(x_{n-1}, T_{m} x\right), D\left(x, T_{n} x_{n-1}\right)\right\} \\
\leqslant & d\left(x, x_{n}\right)+a_{n, m} \max \left\{d\left(x_{n-1}, x\right), d\left(x_{n-1}, x_{n}\right), D\left(x, T_{m} x\right), D\left(x_{n-1}, T_{m} x\right), d\left(x, x_{n}\right)\right\} .
\end{aligned}
$$

Taking $\overline{\lim }$ as $n \rightarrow \infty$, we obtain $D\left(x, T_{m} x\right) \leqslant\left(\overline{\lim }_{n \rightarrow \infty} a_{n, m}\right) D\left(x, T_{m} x\right)$, which implies $D\left(x, T_{m} x\right)=0$. This means that $x \in T_{m} x$ and the proof is complete.

Theorem 3. Let $(X, d)$ be a complete metric space and $0 \leqslant a_{i, j}, 0<b_{i, j}(i, j=1,2, \ldots)$ with $a_{i, i+1} \neq 1$ for all $i=1,2, \ldots$ satisfy:

(i) for each $j, \overline{\lim }_{i \rightarrow \infty} a_{i, j}<1$ and $\overline{\lim }_{i \rightarrow \infty} b_{i, j}<\infty$;

(ii) $\sum_{n=1}^{\infty} A_{n}<\infty$ where $A_{n}=\prod_{i=1}^{n} \frac{b_{i, i+1}}{1-a_{i, i+1}}$.

Let $\alpha: X \times X \rightarrow[0, \infty)$ be a given function and $\left\{T_{n}\right\}$ be a sequence of multi-valued operators $T_{n}: X \rightarrow \mathcal{C} \mathcal{L}(X)(n=$ $1,2, \ldots)$ such that

$$
\alpha(x, y) \mathcal{H}\left(T_{i} x, T_{j} y\right) \leqslant a_{i, j} D\left(y, T_{j} y\right) \varphi\left(D\left(x, T_{i} x\right), d(x, y)\right)+b_{i, j} d(x, y),
$$

for all $x, y \in X ; i, j=1,2, \ldots$ with $x \neq y$ and $i \neq j$, where $\varphi:[0, \infty) \times[0, \infty) \rightarrow[0, \infty)$ is a continuous function such that $\varphi(t, t)=1$ for all $t \in[0, \infty)$ and for any $t_{1}, s_{1}, t_{2}, s_{2} \in[0, \infty)$,

$$
t_{1} \leqslant t_{2}, s_{1}=s_{2} \Longrightarrow \varphi\left(t_{1}, s_{1}\right) \leqslant \varphi\left(t_{2}, s_{2}\right) .
$$

Moreover, assume that the following assertions hold:

(iii) there exist $x_{0} \in X$ and $x_{1} \in T_{1} x_{0}$ with $x_{0} \neq x_{1}$ and $\alpha\left(x_{0}, x_{1}\right) \geqslant 1$;

(iv) $\left\{T_{n}\right\}$ is $\alpha$-admissible;

(v) for each sequence $\left\{x_{n}\right\}$ in $X$ with $\alpha\left(x_{n}, x_{n+1}\right) \geqslant 1$ for all $n$ and $x_{n} \rightarrow x$, we have $\alpha\left(x_{n}, x\right) \geqslant 1$ for all $n$.

Then each $T_{n}$ have a common fixed point in $X$.

Proof. By (iii) and (5), we have

$$
\begin{aligned}
D\left(x_{1}, T_{2} x_{1}\right) & \leqslant \alpha\left(x_{0}, x_{1}\right) \mathcal{H}\left(T_{1} x_{0}, T_{2} x_{1}\right) \\
& \leqslant a_{1,2} D\left(x_{1}, T_{2} x_{1}\right) \varphi\left(D\left(x_{0}, T_{1} x_{0}\right), d\left(x_{0}, x_{1}\right)\right)+b_{1,2} d\left(x_{0}, x_{1}\right) \\
& \leqslant a_{1,2} D\left(x_{1}, T_{2} x_{1}\right) \varphi\left(d\left(x_{0}, x_{1}\right), d\left(x_{0}, x_{1}\right)\right)+b_{1,2} d\left(x_{0}, x_{1}\right) \\
& \leqslant a_{1,2} D\left(x_{1}, T_{2} x_{1}\right)+b_{1,2} d\left(x_{0}, x_{1}\right)
\end{aligned}
$$

which gives us

$$
D\left(x_{1}, T_{2} x_{1}\right) \leqslant \frac{b_{1,2}}{1-a_{1,2}} d\left(x_{0}, x_{1}\right)<\frac{b_{1,2}}{1-a_{1,2}} p d\left(x_{0}, x_{1}\right),
$$

where $p>1$ is a fixed number. From the above inequality, there exists $x_{2} \in T_{2} x_{1}$ such that $d\left(x_{1}, x_{2}\right)<$ $\frac{b_{1,2}}{1-a_{1,2}} p d\left(x_{0}, x_{1}\right)$. Similarly,

$$
D\left(x_{2}, T_{3} x_{2}\right) \leqslant \frac{b_{2,3}}{1-a_{2,3}} d\left(x_{1}, x_{2}\right)<\frac{b_{2,3}}{1-a_{2,3}} \frac{b_{1,2}}{1-a_{1,2}} p d\left(x_{0}, x_{1}\right),
$$


and so there exists $x_{3} \in T_{3} x_{2}$ such that $d\left(x_{2}, x_{3}\right)<\frac{b_{2,3}}{1-a_{2,3}} \frac{b_{1,2}}{1-a_{1,2}} p d\left(x_{0}, x_{1}\right)$. Continuing this process, we obtain a sequence $\left\{x_{n}\right\}$ in $X$ such that $x_{n+1} \in T_{n+1} x_{n}, \alpha\left(x_{n}, x_{n+1}\right) \geqslant 1$, and

$$
d\left(x_{n}, x_{n+1}\right)<A_{n} p d\left(x_{0}, x_{1}\right), \quad \text { for all } n=1,2, \ldots .
$$

Again, as in the proof of Theorem 1, we conclude that $\left\{x_{n}\right\}$ is a Cauchy sequence, and so there exists $x \in X$ such that $x_{n} \rightarrow x$. From the assumption $(v)$, we get $\alpha\left(x_{n}, x\right) \geqslant 1$ for all $n$. To show that $x$ is a common fixed point of $T_{n}$, let $m$ be an arbitrary positive integer. Then, for any $n \in \mathbb{N}$, we have

$$
\begin{aligned}
D\left(x, T_{m} x\right) & \leqslant d\left(x, x_{n}\right)+D\left(x_{n}, T_{m} x\right) \leqslant d\left(x, x_{n}\right)+\alpha\left(x_{n-1}, x\right) \mathcal{H}\left(T_{n} x_{n-1}, T_{m} x\right) \\
& \leqslant d\left(x, x_{n}\right)+a_{n, m} D\left(x, T_{m} x\right) \varphi\left(D\left(x_{n-1}, T_{n} x_{n-1}\right) d\left(x_{n-1}, x\right)\right)+b_{n, m} d\left(x_{n-1}, x\right) \\
& \leqslant d\left(x, x_{n}\right)+a_{n, m} D\left(x, T_{m} x\right) \varphi\left(d\left(x_{n-1}, x_{n}\right), d\left(x_{n-1}, x\right)\right)+b_{n, m} d\left(x_{n-1}, x\right) .
\end{aligned}
$$

Taking $\overline{\lim }$ in both sides of the above inequality, as $n \rightarrow \infty$, we obtain

$$
D\left(x, T_{m} x\right) \leqslant\left(\overline{\lim }_{n \rightarrow \infty} a_{n, m}\right) D\left(x, T_{m} x\right) .
$$

We conclude $D\left(x, T_{m} x\right)=0$ and thus $x \in T_{m} x$.

\section{Common Endpoint Theorems}

The notion of endpoints of multi-valued mappings has been studied by some researchers in the last decade (see for instance, [17-19]). In current section, we state and prove some common endpoint theorems for a sequence of multi-valued mappings with the contractions mentioned in Section 2. We need the following definition.

Definition 2. Let $T_{n}: X \rightarrow \mathcal{C L}(X)(n=1,2, \ldots)$ be a sequence of multi-valued mappings. We say that $\left\{T_{n}\right\}$ has (HS) property whenever for each $x \in X$ there exists $y \in T_{n} x$ such that $\mathcal{H}\left(T_{n} x, T_{n+1} y\right) \geqslant \sup _{b \in T_{n+1} y} d(y, b)$.

Theorem 4. Let $(X, d)$ be a complete metric space and $0 \leqslant a_{i, j}(i, j=1,2, \ldots)$ with $a_{i, i+1} \neq 1$ for all $i=$ $1,2, \ldots$ satisfy:

(i) for each (j), $\overline{\lim }_{i \rightarrow \infty} a_{i, j}<1$;

(ii) $\sum_{n=1}^{\infty} A_{n}<\infty$ where $A_{n}=\prod_{i=1}^{n} \frac{a_{i, i+1}}{1-a_{i, i+1}}$.

Let $\alpha: X \times X \rightarrow[0, \infty)$ be a given function and $\left\{T_{n}\right\}$ be a sequence of multi-valued operators $T_{n}: X \rightarrow \mathcal{C} \mathcal{L}(X)(n=$ $1,2, \ldots)$ satisfying $(H S)$ property such that

$$
\alpha(x, y) \mathcal{H}\left(T_{i} x, T_{j} y\right) \leqslant a_{i, j}\left[D\left(x, T_{j} y\right)+D\left(y, T_{i} x\right)\right],
$$

for all $x, y \in X ; i, j=1,2, \ldots$ with $x \neq y$ and $i \neq j$. Moreover, assume that the following assertions hold:

(iii) there exists $x_{0} \in X$ such that for any $x \in T_{1} x_{0}$, we have $\alpha\left(x_{0}, x\right) \geqslant 1$;

(iv) $\left\{T_{n}\right\}$ is $\alpha$-admissible;

(v) for each sequence $\left\{x_{n}\right\}$ in $X$ with $\alpha\left(x_{n}, x_{n+1}\right) \geqslant 1$ for all $n$ and $x_{n} \rightarrow x$, we have $\alpha\left(x_{n}, x\right) \geqslant 1$ for all $n$.

Then each $T_{n}$ have a common endpoint in $X$.

Proof. Since $\left\{T_{n}\right\}$ has (HS) property, there exists $x_{1} \in T_{1} x_{0}$ such that $\mathcal{H}\left(T_{1} x_{0}, T_{2} x_{1}\right) \geqslant \sup _{b \in T_{2} x_{1}} d\left(x_{1}, b\right)$. From (iii), we have $\alpha\left(x_{0}, x_{1}\right) \geqslant 1$. Similarly, there exists $x_{2} \in T_{2} x_{1}$ such 
that $\mathcal{H}\left(T_{2} x_{1}, T_{3} x_{2}\right) \geqslant \sup _{b \in T_{3} x_{2}} d\left(x_{2}, b\right)$. Since $\left\{T_{n}\right\}$ is $\alpha$-admissible, so $\alpha\left(x_{1}, x_{2}\right) \geqslant 1$. If we continue this process, we obtain a sequence $\left\{x_{n}\right\}$ in $X$ such that $x_{n} \in T_{n} x_{n-1}, \alpha\left(x_{n-1}, x_{n}\right) \geqslant 1$, and

$$
\mathcal{H}\left(T_{n} x_{n-1}, T_{n+1} x_{n}\right) \geqslant \sup _{b \in T_{n+1} x_{n}} d\left(x_{n}, b\right),
$$

for all $n \geqslant 1$. Then we have

$$
\begin{aligned}
d\left(x_{n}, x_{n+1}\right) & \leqslant \sup _{b \in T_{n+1} x_{n}} d\left(x_{n}, b\right) \leqslant \alpha\left(x_{n-1}, x_{n}\right) \mathcal{H}\left(T_{n} x_{n-1}, T_{n+1} x_{n}\right) \\
& \leqslant a_{n, n+1}\left[D\left(x_{n-1}, T_{n+1} x_{n}\right)+D\left(x_{n}, T_{n} x_{n-1}\right)\right] \\
& \leqslant a_{n, n+1}\left[d\left(x_{n-1}, x_{n+1}\right)\right] \leqslant a_{n, n+1}\left[d\left(x_{n-1}, x_{n}\right)+d\left(x_{n}, x_{n+1}\right)\right] .
\end{aligned}
$$

From the above inequality, we get

$$
d\left(x_{n}, x_{n+1}\right) \leqslant \frac{a_{n, n+1}}{1-a_{n, n+1}} d\left(x_{n-1}, x_{n}\right) \leqslant \ldots \leqslant A_{n} d\left(x_{0}, x_{1}\right) .
$$

Hence $\left\{x_{n}\right\}$ is a Cauchy sequence, and so there exists $x \in X$ such that $x_{n} \rightarrow x$. From (v) we deduce $\alpha\left(x_{n}, x\right) \geqslant 1$ for all $n$. Now we show that $x$ is a common endpoint of $T_{n}$. Let $m \in \mathbb{N}$ be arbitrary. Then, for any $n \in \mathbb{N}$, we have

$$
\begin{aligned}
\mathcal{H}\left(\{x\}, T_{m} x\right) \leqslant & d\left(x, x_{n}\right)+\mathcal{H}\left(\left\{x_{n}\right\}, T_{n+1} x_{n}\right)+\alpha\left(x_{n}, x\right) \mathcal{H}\left(T_{n+1} x_{n}, T_{m} x\right) \\
\leqslant & d\left(x, x_{n}\right)+\alpha\left(x_{n-1}, x_{n}\right) \mathcal{H}\left(T_{n} x_{n-1}, T_{n+1} x_{n}\right)+\alpha\left(x_{n}, x\right) \mathcal{H}\left(T_{n+1} x_{n}, T_{m} x\right) \\
\leqslant & d\left(x, x_{n}\right)+a_{n, n+1}\left[D\left(x_{n-1}, T_{n+1} x_{n}\right)+D\left(x_{n}, T_{n} x_{n-1}\right)\right] \\
& +a_{n+1, m}\left[D\left(x_{n}, T_{m} x\right)+D\left(x, T_{n+1} x_{n}\right)\right] \\
\leqslant & d\left(x, x_{n}\right)+a_{n, n+1}\left[d\left(x_{n-1}, x_{n+1}\right)\right]+a_{n+1, m}\left[D\left(x_{n}, T_{m} x\right)+d\left(x, x_{n+1}\right)\right] .
\end{aligned}
$$

Taking $\overline{\lim }$ as $n \rightarrow \infty$, we obtain

$$
\mathcal{H}\left(\{x\}, T_{m} x\right) \leqslant\left(\overline{\lim }_{n \rightarrow \infty} a_{n+1, m}\right) D\left(x, T_{m} x\right) \leqslant\left(\overline{\lim }_{n \rightarrow \infty} a_{n+1, m}\right) \mathcal{H}\left(\{x\}, T_{m} x\right),
$$

which implies $\mathcal{H}\left(\{x\}, T_{m} x\right)=0$ and so $T_{m} x=\{x\}$. Since $m$ was arbitrary, the proof is complete.

Theorem 5. In the statement of Theorem 4 , if we add the extra condition $\alpha(x, y) \geqslant 1$ for any common endpoints $x, y$ of $T_{n}$, then the common endpoint of $T_{n}$ is unique.

Proof. Let $x, y$ be two common endpoints of $T_{n}$. Since $\sum_{n=1}^{\infty} A_{n}<\infty$, there exists $i_{0} \in \mathbb{N}$ such that $\frac{a_{i_{0}, i_{0}+1}}{1-a_{i_{0}, i_{0}+1}}<1$, which implies $a_{i_{0}, i_{0}+1}<\frac{1}{2}$. Then, using (7), we get

$$
\begin{aligned}
d(x, y) & =\mathcal{H}\left(T_{i} x, T_{i_{0}+1} y\right) \\
& \leqslant \alpha(x, y) \mathcal{H}\left(T_{i_{0}} x, T_{i_{0}+1} y\right) \\
& \leqslant a_{i_{0}, i_{0}+1}\left[D\left(x, T_{i_{0}+1} y\right)+D\left(y, T_{i_{0}} x\right)\right] \\
& =2 a_{i_{0}, i_{0}+1} d(x, y)
\end{aligned}
$$

which implies $d(x, y)=0$ and so $x=y$. 
Example 1. Consider the space $X=[0,1]$ with the usual metric $d(x, y)=|x-y|$. Define a sequence of mappings $T_{n}: X \rightarrow \mathcal{C} \mathcal{L}(X)$ by

$$
T_{n}(x)= \begin{cases}\{1\}, & \frac{1}{2} \leqslant x \leqslant 1, \\ {\left[\frac{2}{3}+\frac{1}{n+2}, 1\right],} & x=0, \\ \{0\}, & 0<x<\frac{1}{2} .\end{cases}
$$

Also consider the constants $a_{i, j}=\frac{1}{3}+\frac{1}{|i-j|+6}$. Then $\overline{\lim }_{i \rightarrow \infty} a_{i, j}=\frac{1}{3}<1$, for all $j \in \mathbb{N} . A_{n}=\prod_{i=1}^{n} \frac{a_{i, i+1}}{1-a_{i, i+1}}=$ $\left(\frac{10}{11}\right)^{n}$. Thus $\sum_{n=1}^{\infty} A_{n}=\sum_{n=1}^{\infty}\left(\frac{10}{11}\right)^{n}<\infty$. Also let

$$
\alpha(x, y)= \begin{cases}1, & x, y \in\{0\} \cup\left[\frac{1}{2}, 1\right] \\ 0, & \text { otherwise. }\end{cases}
$$

Now we show that $\alpha(x, y) \mathcal{H}\left(T_{i} x, T_{j} y\right) \leqslant a_{i, j}\left[D\left(x, T_{j} y\right)+D\left(y, T_{i} x\right)\right]$, for all $x, y \in X$. If $0<x<\frac{1}{2}$ or $0<y<\frac{1}{2}$, then $\alpha(x, y)=0$ and we have nothing to prove. Therefore, we may assume $x, y \in\{0\} \cup\left[\frac{1}{2}, 1\right]$. We consider the following cases:

(1) $x, y \in\left[\frac{1}{2}, 1\right]$. In this case we have $\alpha(x, y) \mathcal{H}\left(T_{i} x, T_{j} y\right)=\mathcal{H}(\{1\},\{1\})=0 \leqslant a_{i, j}\left[D\left(x, T_{j} y\right)+D\left(y, T_{i} x\right)\right]$, for all $x, y \in X$.

(2) $x \in\left[\frac{1}{2}, 1\right]$ and $y=0$. In this case we have

$$
\begin{aligned}
\alpha(x, y) \mathcal{H}\left(T_{i} x, T_{j} y\right) & =\mathcal{H}\left(\{1\},\left[\frac{2}{3}+\frac{1}{j+2}, 1\right]\right) \\
& =\left|1-\left(\frac{2}{3}+\frac{1}{j+2}\right)\right|=\frac{1}{3}-\frac{1}{j+2} \leqslant \frac{1}{3} \\
& \leqslant\left(\frac{1}{3}+\frac{1}{|i-j|+6}\right)\left(\left|x-\left(\frac{2}{3}+\frac{1}{j+2}\right)\right|+|0-1|\right) \\
& =a_{i, j}\left[D\left(x, T_{j} y\right)+D\left(y, T_{i} x\right) .\right.
\end{aligned}
$$

(3) $x=y=0, i<j$. Then

$$
\begin{aligned}
\alpha(x, y) \mathcal{H}\left(T_{i} x, T_{j} y\right) & =\left|\frac{2}{3}+\frac{1}{j+2}-\left(\frac{2}{3}+\frac{1}{i+2}\right)\right|=\frac{1}{i+2}-\frac{1}{j+2} \leqslant \frac{1}{i+2} \\
& \leqslant\left(\frac{1}{3}+\frac{1}{|i-j|+6}\right)\left(\frac{2}{3}+\frac{1}{i+2}+\left(\frac{2}{3}+\frac{1}{j+2}\right)\right) \\
& =a_{i, j}\left[D\left(x, T_{j} y\right)+D\left(y, T_{i} x\right)\right] .
\end{aligned}
$$

Also for $x_{0}=0$ and $x_{1}=1$, we have $x_{1} \in\{1\}=\left[\frac{2}{3}+\frac{1}{1+2}, 1\right]=T_{1} x_{0}$ and $\alpha(x, y)=1 \geqslant 1$. It is easy to check that $\left\{T_{n}\right\}$ is $\alpha$-admissible. Also, for any common endpoints $x, y$, we have $\alpha(x, y) \geqslant 1$. Thus, all of the conditions of Theorem 4 and Theorem 5 are satisfied. Therefore, the mappings $T_{n}$ have a unique common endpoint. Here $x=1$ is the unique common endpoint of $T_{n}$.

Theorem 6. Let $(X, d)$ be a complete metric space and $0 \leqslant a_{i, j}(i, j=1,2, \ldots)$ with $a_{i, i+1} \neq 1$ for all $i=$ $1,2, \ldots$ satisfy:

(i) for each (j), $\overline{\lim }_{i \rightarrow \infty} a_{i, j}<1$;

(ii) $\sum_{n=1}^{\infty} A_{n}<\infty$ where $A_{n}=\prod_{i=1}^{n} \frac{a_{i, i+1}}{1-a_{i, i+1}}$. 
Let $\alpha: X \times X \rightarrow[0, \infty)$ be a given function and $\left\{T_{n}\right\}$ be a sequence of multi-valued operators $T_{n}: X \rightarrow \mathcal{C} \mathcal{L}(X)(n=$ $1,2, \ldots)$ satisfying (HS) property such that

$$
\alpha(x, y) \mathcal{H}\left(T_{i} x, T_{j} y\right) \leqslant a_{i, j} \max \left\{d(x, y), D\left(x, T_{i} x\right), D\left(y, T_{j} y\right), D\left(x, T_{j} y\right), D\left(y, T_{i} x\right)\right\},
$$

for all $x, y \in X ; i, j=1,2, \ldots$ with $x \neq y$ and $i \neq j$. Moreover, assume that the following assertions hold:

(iii) there exists $x_{0} \in X$ such that for any $x \in T_{1} x_{0}$, we have $\alpha\left(x_{0}, x\right) \geqslant 1$;

(iv) $\left\{T_{n}\right\}$ is $\alpha$-admissible;

(v) for each sequence $\left\{x_{n}\right\}$ in $X$ with $\alpha\left(x_{n}, x_{n+1}\right) \geqslant 1$ for all $n$ and $x_{n} \rightarrow x$, we have $\alpha\left(x_{n}, x\right) \geqslant 1$ for all $n$.

Then each $T_{n}$ have a common endpoint in $X$.

Proof. As in the proof of Theorem 4, there exists a sequence $\left\{x_{n}\right\}$ in $X$ such that $x_{n} \in T_{n} x_{n-1}, \alpha\left(x_{n-1}, x_{n}\right) \geqslant$ 1 , and

$$
\mathcal{H}\left(T_{n} x_{n-1}, T_{n+1} x_{n}\right) \geqslant \sup _{b \in T_{n+1} x_{n}} d\left(x_{n}, b\right)
$$

for all $n \geqslant 1$. Then we have

$$
\begin{aligned}
d\left(x_{n}, x_{n+1}\right) \leqslant & \sup _{b \in T_{n+1} x_{n}} d\left(x_{n}, b\right) \leqslant \alpha\left(x_{n-1}, x_{n}\right) \mathcal{H}\left(T_{n} x_{n-1}, T_{n+1} x_{n}\right) \\
\leqslant & a_{n, n+1} \max \left\{d\left(x_{n-1}, x_{n}\right), D\left(x_{n-1}, T_{n} x_{n-1}\right), D\left(x_{n}, T_{n+1} x_{n}\right),\right. \\
& \left.D\left(x_{n-1}, T_{n+1} x_{n}\right), D\left(x_{n}, T_{n} x_{n-1}\right)\right\} \\
\leqslant & a_{n, n+1}\left[d\left(x_{n-1}, x_{n}\right)+d\left(x_{n}, x_{n+1}\right)\right] .
\end{aligned}
$$

From the above inequality, we get

$$
d\left(x_{n}, x_{n+1}\right) \leqslant \frac{a_{n, n+1}}{1-a_{n, n+1}} d\left(x_{n-1}, x_{n}\right) \leqslant \ldots \leqslant A_{n} d\left(x_{0}, x_{1}\right) .
$$

Thus, $\left\{x_{n}\right\}$ is a Cauchy sequence and so there exists $x \in X$ such that $x_{n} \rightarrow x$ and $\alpha\left(x_{n}, x\right) \geqslant 1$ for all $n$. Now, we show that $x$ is a common endpoint of $T_{n}$. Let $m \in \mathbb{N}$ be arbitrary. Then, for any $n \in \mathbb{N}$, we have

$$
\begin{aligned}
\mathcal{H}\left(\{x\}, T_{m} x\right) \leqslant & d\left(x, x_{n}\right)+\mathcal{H}\left(\left\{x_{n}\right\}, T_{n+1} x_{n}\right)+\alpha\left(x_{n}, x\right) \mathcal{H}\left(T_{n+1} x_{n}, T_{m} x\right) \\
\leqslant & d\left(x, x_{n}\right)+\alpha\left(x_{n-1}, x_{n}\right) \mathcal{H}\left(T_{n} x_{n-1}, T_{n+1} x_{n}\right)+\alpha\left(x_{n}, x\right) \mathcal{H}\left(T_{n+1} x_{n}, T_{m} x\right) \\
\leqslant & d\left(x, x_{n}\right)+a_{n, n+1}\left[d\left(x_{n-1}, x_{n}\right)+d\left(x_{n}, x_{n+1}\right)\right] \\
& +a_{n+1, m} \max \left\{d\left(x_{n}, x\right), D\left(x_{n}, T_{n+1} x_{n}\right), D\left(x, T_{m} x\right), D\left(x_{n}, T_{m} x\right), D\left(x, T_{n+1} x_{n}\right)\right\} \\
\leqslant & d\left(x, x_{n}\right)+a_{n, n+1}\left[d\left(x_{n-1}, x_{n}\right)+d\left(x_{n}, x_{n+1}\right)\right] \\
& +a_{n+1, m} \max \left\{d\left(x_{n}, x\right), D\left(x_{n}, x_{n+1}\right), D\left(x, T_{m} x\right), D\left(x_{n}, T_{m} x\right), D\left(x, x_{n+1}\right)\right\} .
\end{aligned}
$$

Taking $\overline{\lim }$ in both sides of the above inequality, as $n \rightarrow \infty$, we obtain

$$
\mathcal{H}\left(\{x\}, T_{m} x\right) \leqslant\left(\overline{\lim }_{n \rightarrow \infty} a_{n+1, m}\right) D\left(x, T_{m} x\right) \leqslant\left(\overline{\lim }_{n \rightarrow \infty} a_{n+1, m}\right) \mathcal{H}\left(\{x\}, T_{m} x\right),
$$

which implies $\mathcal{H}\left(\{x\}, T_{m} x\right)=0$ and so $T_{m} x=\{x\}$.

Theorem 7. With the conditions of Theorem 6 , if we add the extra condition $\alpha(x, y) \geqslant 1$ for any common endpoints $x, y$ of $T_{n}$, then the common endpoint of $T_{n}$ is unique. 
Proof. Let $x, y$ be two common endpoints of $T_{n}$. Using (9), we get

$$
\begin{aligned}
d(x, y) & =\mathcal{H}\left(T_{i} x, T_{j} y\right) \leqslant \alpha(x, y) \mathcal{H}\left(T_{i} x, T_{j} y\right) \\
& \leqslant a_{i, j} \max \left\{d(x, y), D\left(x, T_{i} x\right), D\left(y, T_{j} y\right), D\left(x, T_{j} y\right), D\left(y, T_{i} x\right)\right\} \\
& =a_{i, j} d(x, y) .
\end{aligned}
$$

Thus, $d(x, y) \leqslant \overline{\lim }_{i \rightarrow \infty} a_{i, j} d(x, y)$, which means that $d(x, y)=0$ and hence $x=y$.

Theorem 8. Let $(X, d)$ be a complete metric space and $0 \leqslant a_{i, j}, 0 \leqslant b_{i, j}(i, j=1,2, \ldots)$ with $a_{i, i+1} \neq 1$ for all $i=1,2, \ldots$ satisfy:

(i) for each (j), $\overline{\lim }_{i \rightarrow \infty} a_{i, j}<1, \overline{\lim }_{i \rightarrow \infty} b_{i, j}<1$;

(ii) $\sum_{n=1}^{\infty} A_{n}<\infty$ where $A_{n}=\prod_{i=1}^{n} \frac{b_{i, i+1}}{1-a_{i, i+1}}$.

Let $\alpha: X \times X \rightarrow[0, \infty)$ be a given function and $\left\{T_{n}\right\}$ be a sequence of multi-valued operators $T_{n}: X \rightarrow \mathcal{C} \mathcal{L}(X)(n=$ $1,2, \ldots)$ satisfying $(H S)$ property such that

$$
\alpha(x, y) \mathcal{H}\left(T_{i} x, T_{j} y\right) \leqslant a_{i, j} D\left(y, T_{j} y\right) \varphi\left(D\left(x, T_{i} x\right), d(x, y)\right)+b_{i, j} d(x, y),
$$

for all $x, y \in X ; i, j=1,2, \ldots$ with $x \neq y$ and $i \neq j$, where $\varphi$ is as in Theorem 3. Moreover, assume that the following assertions hold:

(iii) there exists $x_{0} \in X$ such that for any $x \in T_{1} x_{0}$, we have $\alpha\left(x_{0}, x\right) \geqslant 1$;

(iv) $\left\{T_{n}\right\}$ is $\alpha$-admissible;

(v) for each sequence $\left\{x_{n}\right\}$ in $X$ with $\alpha\left(x_{n}, x_{n+1}\right) \geqslant 1$ for all $n$ and $x_{n} \rightarrow x$, we have $\alpha\left(x_{n}, x\right) \geqslant 1$ for all $n$.

Then each $T_{n}$ have a common endpoint in $X$.

Proof. As in the proof of Theorem 4, there exists a sequence $\left\{x_{n}\right\}$ in $X$ such that $x_{n} \in T_{n} x_{n-1}, \alpha\left(x_{n-1}, x_{n}\right) \geqslant$ 1 , and

$$
\mathcal{H}\left(T_{n} x_{n-1}, T_{n+1} x_{n}\right) \geqslant \sup _{b \in T_{n+1} x_{n}} d\left(x_{n}, b\right)
$$

for all $n \geqslant 1$. Then we have

$$
\begin{aligned}
d\left(x_{n}, x_{n+1}\right) & \leqslant \sup _{b \in T_{n+1} x_{n}} d\left(x_{n}, b\right) \\
& \leqslant \alpha\left(x_{n-1}, x_{n}\right) \mathcal{H}\left(T_{n} x_{n-1}, T_{n+1} x_{n}\right) \\
& \leqslant a_{n, n+1} D\left(x_{n}, T_{n+1} x_{n}\right) \varphi\left(D\left(x_{n-1}, T_{n} x_{n-1}\right), d\left(x_{n-1}, x_{n}\right)\right)+b_{n, n+1} d\left(x_{n-1}, x_{n}\right) \\
& \leqslant a_{n, n+1} d\left(x_{n}, x_{n+1}\right)+b_{n, n+1} d\left(x_{n-1}, x_{n}\right) .
\end{aligned}
$$

From the above inequality, we get

$$
d\left(x_{n}, x_{n+1}\right) \leqslant \frac{b_{n, n+1}}{1-a_{n, n+1}} d\left(x_{n-1}, x_{n}\right) \leqslant \ldots \leqslant A_{n} d\left(x_{0}, x_{1}\right) .
$$


As in proof of Theorem 1, we conclude that $\left\{x_{n}\right\}$ is a Cauchy sequence, and so there exists $x \in X$ such that $x_{n} \rightarrow x$ and $\alpha\left(x_{n}, x\right) \geqslant 1$ for all $n$. To show that $x$ is a common endpoint of $T_{n}$, consider an arbitrary natural number $m$. Then, for any $n \in \mathbb{N}$, we have

$$
\begin{aligned}
\mathcal{H}\left(\{x\}, T_{m} x\right) \leqslant & d\left(x, x_{n}\right)+\mathcal{H}\left(\left\{x_{n}\right\}, T_{n+1} x_{n}\right)+\alpha\left(x_{n}, x\right) \mathcal{H}\left(T_{n+1} x_{n}, T_{m} x\right) \\
\leqslant & d\left(x, x_{n}\right)+\alpha\left(x_{n-1}, x_{n}\right) \mathcal{H}\left(T_{n} x_{n-1}, T_{n+1} x_{n}\right)+\alpha\left(x_{n}, x\right) \mathcal{H}\left(T_{n+1} x_{n}, T_{m} x\right) \\
\leqslant & d\left(x, x_{n}\right)+a_{n, n+1} D\left(x_{n}, T_{n+1} x_{n}\right) \varphi\left(D\left(x_{n-1}, T_{n} x_{n-1}\right), d\left(x_{n-1}, x_{n}\right)\right) \\
& +b_{n, n+1} d\left(x_{n-1}, x_{n}\right) \\
& +a_{n+1, m} D\left(x, T_{m} x\right) \varphi\left(D\left(x_{n}, T_{n+1} x_{n}\right), d\left(x_{n}, x\right)\right)+b_{n+1, m} d\left(x_{n}, x\right) \\
\leqslant & d\left(x, x_{n}\right)+a_{n, n+1} d\left(x_{n}, x_{n+1}\right)+b_{n, n+1} d\left(x_{n-1}, x_{n}\right) \\
& +a_{n+1, m} D\left(x, T_{m} x\right) \varphi\left(d\left(x_{n}, x_{n+1}\right), d\left(x_{n}, x\right)\right)+b_{n+1, m} d\left(x_{n}, x\right) .
\end{aligned}
$$

Taking $\overline{\lim }$ as $n \rightarrow \infty$, we obtain

$$
\begin{aligned}
\mathcal{H}\left(\{x\}, T_{m} x\right) & \leqslant\left(\overline{\lim }_{n \rightarrow \infty} a_{n+1, m}\right) D\left(x, T_{m} x\right) \\
& \leqslant\left(\overline{\lim }_{n \rightarrow \infty} a_{n+1, m}\right) \mathcal{H}\left(\{x\}, T_{m} x\right),
\end{aligned}
$$

which shows $\mathcal{H}\left(\{x\}, T_{m} x\right)=0$. Thus $T_{m} x=\{x\}$.

Theorem 9. In the statement of Theorem 8 , if we add the extra condition $\alpha(x, y) \geqslant 1$ for any common endpoints $x, y$ of $T_{n}$, then the common endpoint of $T_{n}$ is unique.

Proof. Let $x, y$ be two common endpoints of $T_{n}$. Using (10), we have

$$
\begin{aligned}
d(x, y) & =\mathcal{H}\left(T_{i} x, T_{j} y\right) \\
& \leqslant \alpha(x, y) \mathcal{H}\left(T_{i} x, T_{j} y\right) \\
& \leqslant a_{i, j} D\left(y, T_{j} y\right) \varphi\left(D\left(x, T_{i} x\right), d(x, y)\right)+b_{i, j} d(x, y) \\
& =b_{i, j} d(x, y) .
\end{aligned}
$$

Therefore, $d(x, y) \leqslant \overline{\lim }_{i \rightarrow \infty} b_{i, j} d(x, y)$. Hence $d(x, y)=0$, which means that $x=y$.

\section{Application to Integral Equations}

Take $I=[0, T]$. Let $X:=C(I, \mathbb{R})$ be the set of all real valued continuous functions with domain $I$. Define the meric $d$ on $X$ with

$$
d(x, y)=\sup _{t \in I}(|x(t)-y(t)|)=\|x-y\| .
$$

Consider the system of integral equation:

$$
x(t)=p(t)+\int_{0}^{T} G(t, s) F_{n}(s, x(s)) d s, \quad t \in I, n=1,2,3, \ldots
$$

Our hypotheses on the data are the following:

(A) $p: I \rightarrow \mathbb{R}$ and $F_{n}: I \times \mathbb{R} \rightarrow \mathbb{R}$ are continuous, for all $n \in \mathbb{N}$;

(B) $G: I \times I \rightarrow \mathbb{R}$ is continuous and measurable at $s \in I$ for all $t \in I$;

(C) $G(t, s) \geqslant 0$ for all $t, s \in I$ and $\int_{0}^{T} G(t, s) d s \leqslant 1$ for all $t \in l$;

(D) there exists $x_{0} \in X$ such that $x_{0}(t) \leqslant \int_{0}^{T} G(t, s) F_{1}\left(s, x_{0}(s)\right) d s$, for all $t \in l$;

(E) for any $x \in X$ with $x(t) \leqslant \int_{0}^{T} G(t, s) F_{n}(s, x(s)) d s$, for all $t \in I$, then we have $\int_{0}^{T} G(t, s) F_{n}(s, x(s)) d s \leqslant \int_{0}^{T} G(t, s) F_{n+1}\left(s, \int_{0}^{T} G(s, \tau) F_{n}(\tau, x(\tau)) d \tau\right) d s$, for all $t \in I$. 
Let $0 \leqslant a_{i, j}(i, j=1,2, \ldots)$ with $a_{i, i+1} \neq 1$ for all $i=1,2, \ldots$ satisfy:

(F) for each (j), $\overline{\lim }_{i \rightarrow \infty} a_{i, j}<1$;

(G) $\sum_{n=1}^{\infty} A_{n}<\infty$ where $A_{n}=\prod_{i=1}^{n} \frac{a_{i, i+1}}{1-a_{i, i+1}}$;

(H) for each $t \in I, x, y \in X$ with $x \leqslant y$, and $i \neq j$, we have

$$
\begin{aligned}
\left|F_{i}(t, x(t))-F_{j}(t, y(t))\right| \leqslant & a_{i, j}\left(\left|x(t)-\int_{0}^{T} G(t, s) F_{j}(s, y(s)) d s\right|\right. \\
& \left.+\left|y(t)-\int_{0}^{T} G(t, s) F_{i}(s, x(s)) d s\right|\right) .
\end{aligned}
$$

Theorem 10. Under the assumptions $(A)-(H)$, the system of integral Equation (11) has a solution in $X$.

Proof. Define $Y_{n}: X \rightarrow X$ as

$$
\left(\mathrm{Y}_{n} x\right)(t)=p(t)+\int_{0}^{T} G(t, s) F_{n}(s, x(s)) d s, \quad t \in I
$$

for all $n \in \mathbb{N}$. In addition, define $\alpha: X \times X \rightarrow[0, \infty)$ by

$$
\alpha(x, y)= \begin{cases}1, & x(t) \leqslant y(t) \text { for all } t \in I \\ 0, & \text { otherwise. }\end{cases}
$$

Let $x, y$ be two arbitrary elements of $X$. If $x \leqslant y$, then $\alpha(x, y)=0$ and so inequality (2) holds, obviously. Now, let $x \leqslant y$. Then

$$
\begin{aligned}
\left|\left(Y_{i} x\right)(t)-\left(\mathrm{Y}_{j} y\right)(t)\right|= & \mid \int_{0}^{T} G(t, s)\left(F_{i}(s, x(s))-F_{j}(s, y(s)) d s \mid\right. \\
\leqslant & \int_{0}^{T} G(t, s)\left|F_{i}(s, x(s))-F_{j}(s, y(s))\right| d s \\
\leqslant & \int_{0}^{T} G(t, s) a_{i, j}\left(\left|x(s)-\int_{0}^{T} G(s, \tau) F_{j}(\tau, y(\tau)) d \tau\right|\right. \\
& \left.+\left|y(s)-\int_{0}^{T} G(s, \tau) F_{i}(\tau, x(\tau)) d \tau\right|\right) d s \\
\leqslant & \left.\int_{0}^{T} G(t, s) a_{i, j}\left(\left|x(s)-\left(\mathrm{Y}_{j} y\right)(s)\right|+\mid y(s)-\mathrm{Y}_{i} x\right)(s) \mid\right) d s \\
\leqslant & \left.\int_{0}^{T} G(t, s) a_{i, j}\left(\left\|x-\left(\mathrm{Y}_{j} y\right)\right\|+\| y-\mathrm{Y}_{i} x\right)(s) \|\right) d s \\
\leqslant & a_{i, j}\left(\left\|x-\mathrm{Y}_{j} y\right\|+\left\|y-\mathrm{Y}_{i} x\right\|\right)
\end{aligned}
$$

for every $t \in I$. Take sup in the above inequality to find that

$$
\begin{aligned}
\alpha(x, y) d\left(\mathrm{Y}_{i} x, \mathrm{Y}_{j} y\right) & =\|\mathrm{Y} x-\mathrm{Y} y\| \\
& \leqslant a_{i, j}\left(\left\|x-\mathrm{Y}_{j} y\right\|+\left\|y-\mathrm{Y}_{i} x\right\|\right)=a_{i, j}\left(d\left(x, \mathrm{Y}_{j} y\right)+d\left(y, \mathrm{Y}_{i} x\right)\right) .
\end{aligned}
$$

The properties $(D)$ and $(E)$ yield that properties (iii) and (iv) of Theorem 1 are satisfied. Obviously, the property $(v)$ of Theorem 1 holds. Thus, by that theorem, $\left\{\mathrm{Y}_{n}\right\}$ have a common fixed point, that is, the system of integral Equation (11) having a solution. 
Author Contributions: Writing-original draft, H.I., B.M., C.P. and V.P.; Writing-review and editing, H.I., B.M., C.P. and V.P. All authors have read and agreed to the published version of the manuscript.

Funding: This research received no external funding.

Conflicts of Interest: The authors declare no conflict of interest.

\section{References}

1. Ćirić, L.B. On a family of contractive maps and fixed points. Publ. Inst. Math. 1974, 17, 45-51.

2. Allahyari, R.; Arab, R.; Haghighi, A.S. Common fixed point theorems for infinite families of contractive maps. Math. Sci. 2015, 9, 199-203. [CrossRef]

3. Nadler, S.B., Jr. Multi-valued contraction mappings. Pac. J. Math. 1969, 30, 475-488. [CrossRef]

4. Amini-Harandi, A.; O'Regan, D. Fixed point theorems for set-valued contraction type maps in metric spaces. Fixed Point Theory Appl. 2010, 2010, 390183. [CrossRef]

5. Işık, H.; Ionescu, C. New type of multivalued contractions with related results and applications. U.P.B. Sci. Bull. Ser. A 2018, 80, 13-22.

6. Işık, H.; Parvaneh, V.; Mohammadi, B.; Altun, I. Common fixed point results for generalized Wardowski type contractive multi-valued mappings. Mathematics 2019, 7, 1130. [CrossRef]

7. Kaddouri, H.; Işık, H.; Beloul, S. On new extensions of F-contraction with application to integral inclusions. U.P.B. Sci. Bull. Ser. A 2019, 81, 31-42.

8. Saleem, N.; Vujakovic, J.; Baloch, W.U.; Radenovic, S. Coincidence point results for multivalued Suzuki type mappings using $\theta$-contraction in $b$-metric spaces. Mathematics 2019, 7, 1017. [CrossRef]

9. Samet, B.; Vetro, C.; Vetro, P. Fixed point theorems for $\alpha-\psi$-contractive type mappings. Nonlinear Anal. 2012, 75 , 2154-2165. [CrossRef]

10. Hasanzade Asl, J.; Rezapour, S.; Shahzad, N. On fixed points of $\alpha-\psi$-contractive multifunctions. Fixed Point Theory Appl. 2012, 2012, 212.

11. Mohammadi, B.; Rezapour, S.; Shahzad, N. Some results on fixed points of $\alpha$ - $\psi$-Ćirić generalized multifunctions. Fixed Point Theory Appl. 2013, 2013, 24. [CrossRef]

12. Bunyawat, A.; Suantai, S. Common fixed points of a countable family of multivalued quasinonexpansive mappings in uniformly convex Banach spaces. Int. J. Comput. Math. 2010, 2274-2279.

13. Bunyawat, A.; Suantai, S. Common fixed points of a finite family of multivalued quasi-nonexpansive mappings in uniformly convex Banach spaces. Bull. Iran. Math. Soc. 2013, 1125-1135.

14. Sagar, P.; Malhotra, S.K. Common fixed points of a countable family of I-nonexpansive multivalued mappings in Banach spaces. Am. J. Appl. Math. Stat. 2014, 2, 239-243. [CrossRef]

15. Wangkeeree, R. Implicit iteration process for finite family of nonexpansive nonself-mappings in Banach spaces. Int. J. Math. Sci. Engg. Appl. 2007, 1, 1-12.

16. Zuo, Z. Iterative approximations for a family of multivalued mappings in Banach spaces. J. Math. Inequal. 2010, 4, 549-560. [CrossRef]

17. Amini-Harandi, A. Endpoints of set-valued contractions in metric spaces. Nonlinear Anal. 2010, 72, 132-134. [CrossRef]

18. Mohammadi, B.; Rezapour, S. Endpoints of Suzuki type quasi-contractive multifunctions. U.P.B. Sci. Bull. Ser. A 2015, 77, 17-20.

19. Moradi, S.; Khojasteh, F. Endpoints of multi-valued generalized weak contraction mappings. Nonlinear Anal. 2011, 74, 2170-2174. [CrossRef]

(C) 2020 by the authors. Licensee MDPI, Basel, Switzerland. This article is an open access article distributed under the terms and conditions of the Creative Commons Attribution (CC BY) license (http:/ / creativecommons.org/licenses/by/4.0/). 